\title{
Risk factors and outcomes associated with chronic obstructive pulmonary disease exacerbations requiring hospitalization
}

\author{
Katayoun Bahadori MD MHSc ${ }^{1}$, J Mark FitzGerald MD FRCPC ${ }^{1,2}$, Robert D Levy MD FRCPC 2,3 , \\ Tharwat Fera MD FRCPC ${ }^{2}$, John Swiston MD FRCPC ${ }^{2}$
}

\begin{abstract}
K Bahadori, JM FitzGerald, RD Levy, T Fera, J Swiston. Risk factors and outcomes associated with chronic obstructive pulmonary disease exacerbations requiring hospitalization. Can Respir J 2009;16(4):e43-e49.
\end{abstract}

BACKGROUND: Acute respiratory exacerbations are the most frequent cause of medical visits, hospitalization and death for chronic obstructive pulmonary disease (COPD) patients and, thus, exert a significant social and economic burden on society.

OBJECTIVE: To identify the risk factors associated with hospital readmission(s) for acute exacerbation(s) of COPD (AECOPD).

METHODS: A review of admission records from three large urban hospitals in Vancouver, British Columbia, identified 310 consecutive patients admitted for an AECOPD between April 1, 2001, and December 31, 2002. Logistic regression analysis was performed to identify risk factors for readmissions following an AECOPD

RESULTS: During the study period, $38 \%$ of subjects were readmitted at least once. The mean $( \pm \mathrm{SD})$ duration from the index admission to the first readmission was $5 \pm 4.08$ months. Comparative analysis among the three hospitals identified a significant difference in readmission rates (54\%, 36\% and 18\%, respectively). Logistic regression analysis revealed that preadmission home oxygen use (OR 2.55 ; $95 \%$ CI 1.45 to 4.42 ; $\mathrm{P}=0.001)$, history of a lung infection within the previous year (OR 1.73; 95\% CI 1.01 to $2.97 ; \mathrm{P}=0.048$ ), other chronic respiratory disease (OR $1.78 ; 95 \%$ CI 1.06 to $2.99 ; \mathrm{P}=0.03$ ) and shorter length of hospital stay (OR 0.97; 95\% CI 0.945 to 0.995 ; $\mathrm{P}=0.021$ ) were independently associated with frequent readmissions for an AECOPD.

CONCLUSIONS: Hospital readmission rates for AECOPD were high. Only four clinical factors were found to be independently associated with COPD readmission. There was significant variability in the readmission rate among hospitals. This variability may be a result of differences in the patient populations that each hospital serves or may reflect variability in health care delivery at different institutions.

Key Words: Chronic obstructive lung disease; Exacerbations; Hospitalization; Risk factors

hronic obstructive pulmonary disease (COPD) is a major cause of disability and death in Canada, and throughout the world. Approximately 500,000 Canadians older than 35 years of age have been diagnosed with COPD, and it is estimated that an almost equal number of middle-aged Canadians may also have COPD, but are not yet aware of it (1). Acute exacerbations of COPD (AECOPD) are the most frequent cause of medical visits, hospitalization and death for COPD patients (2). While the length of stay (LOS) for hospitalizations as a

\section{Facteurs de risque et résultantes des poussées de bronchopneumopathie obstructive chronique nécessitant hospitalisation}

HISTORIQUE : Les poussées aiguës de maladies respiratoires sont la plus fréquente cause de consultations médicales, d'hospitalisations et de décès chez les personnes souffrant de bronchopneumopathie obstructive chronique (BPOC) et constituent de ce fait un lourd fardeau social et économique.

OBJECTIF : Reconnaître les facteurs de risque associés aux réhospitalisations pour poussées aiguës de BPOC.

MÉTHODES : Un survol des dossiers d'admission de trois grands hôpitaux urbains de Vancouver, en Colombie-Britannique, a permis de recenser 310 patients consécutifs admis pour poussées aiguës de BPOC entre le $1^{\mathrm{er}}$ avril 2001 et le 31 décembre 2002. Une analyse de régression logistique a été réalisée afin de déterminer les facteurs de risque de réadmission après une poussée aiguë de BPOC.

RÉSULTATS : Durant la période de l'étude, $38 \%$ des sujets ont été réadmis au moins une fois. L'intervalle moyen $( \pm$ É. $-T$. $)$ entre l'admission initiale et la première réadmission a été de $5 \pm 4,08$ mois. Une analyse comparative entre les trois hôpitaux a révélé une différence significative quant au taux de réadmissions ( $54 \%, 36 \%$ et $18 \%$, respectivement). L'analyse de régression logistique a révélé que l'utilisation d'oxygène à domicile avant l'admission (RC 2,55, IC à $95 \%, 1,45$ à 4,42, p = 0,001), des antécédents d'infection pulmonaire au cours de l'année précédente ( RC 1,73 , IC à $95 \%, 1,01$ à 2,97, p = 0,048), d'autres maladies respiratoires chroniques ( $\mathrm{RC} 1,78$, IC à $95 \%, 1,06$ à $2,99, \mathrm{p}=0,03)$ et un séjour hospitalier plus bref ( $\mathrm{RC}$ 0,97, IC à $95 \%, 0,945$ à 0,995, p = 0,021) étaient liés de manière indépendante aux réadmissions fréquentes pour poussées aiguës de BPOC.

CONCLUSIONS : Les taux de réhospitalisations pour poussées aiguës de BPOC ont été élevés. Quatre facteurs cliniques seulement se sont révélés associés de façon indépendante aux réadmissions pour BPOC. On a noté une variabilité significative quant aux taux de réadmissions entre les hôpitaux. Cette variabilité pourrait résulter de différences entre les populations de patients desservies par les hôpitaux ou être le reflet des pratiques thérapeutiques respectives des établissements.

result of AECOPD has been decreasing in Canada in recent years $(3,4)$, the total number of hospitalizations has increased (5). Despite the tremendous burden of hospital admissions, little is known regarding the factors associated with hospital admission and readmissions.

In a recent systematic review (6), we examined the published literature pertaining to risk factors for hospitalization and readmission of COPD patients from 1966 to 2006. A review of 17 relevant studies evaluating the hospitalization of

${ }^{1}$ Centre for Clinical Epidemiology and Evaluation, Vancouver Coastal Health Research Institute and Respiratory Medicine, Vancouver General

Hospital; ${ }^{2}$ Division of Respiratory Medicine, University of British Columbia; ${ }^{3}$ Division of Respiratory Medicine, St Paul's Hospital, Vancouver, British Columbia

Correspondence: Dr John Swiston, Division of Respirology, University of British Columbia, Vancouver General Hospital, 2775 Laurel Street, 7th Floor, Vancouver, British Columbia V5Z 1M9. Telephone 604-875-4122, fax 604-875-4695, e-mail swiston@interchange.ubc.ca 
COPD patients showed significant differences in risk factors reported and associations identified, and found few risk factors that have consistently demonstrated a clear association with admission and readmission. As an example, long-term home use of supplemental oxygen (LTOT) and inhaled corticosteroids were independently associated with admission or a shorter time to first readmission for AECOPD in some of the reviewed studies (7-11). However, in other studies, these associations were not significant or they did not remain significant after an adjustment for potentially confounding factors $(7,12,13)$. Similarly, patient management by a respirologist, lower forced expiratory volume in $1 \mathrm{~s}\left(\mathrm{FEV}_{1}\right)$ and oral corticosteroid use were also associated with a higher risk of readmission in some studies (7-9,13-17) but not others $(7,9,14,18,19)$. These inconsistencies and a need for better definition of the determinants of health in COPD patients within the context of the Canadian health care system, led us to undertake the current study.

The aims of the present study were to ascertain the rates of hospital readmissions for AECOPD among a cohort of patients previously hospitalized with the same diagnosis and to identify risk factors associated with recurrent hospital admissions for AECOPD.

\section{Design and subjects}

\section{METHODS}

The charts of all patients who were admitted for an AECOPD to three general hospitals in the Vancouver, British Columbia, area over a 20-month period between April 1, 2001, and December 31, 2002, were retrospectively reviewed. The index hospitalization was defined as the patient's first admission to an acute care hospital with a primary diagnosis of an AECOPD using the International Classification of Diseases 9th Revision Clinical Modification (ICD-9-CM) coding. The following ICD9-CM codes were included in the present study: 490, 491 (491.0, 491.1, 491.2, 491.20, 491.21), 492 and 496. The index discharge date was defined as the date on which the patient was discharged for the AECOPD. Both COPD patients with a first-episode exacerbation and repeat admissions for subsequent exacerbations were included.

Patients were excluded from the study if they were older than 95 years of age or had a history of asthma. Admissions were excluded from analysis if the hospitalization was primarily for elective surgery and the diagnosis of COPD was coincidental, if the admission was the result of a transfer from another acute care hospital, if the patient was discharged to another acute care hospital or if the patient signed themselves out against medical advice. The protocol was approved by the Ethics Committees of the participating hospitals as well as the University of British Columbia's Clinical Ethics Committee (Vancouver, British Columbia).

\section{Characteristics of the three general hospitals}

Hospital A is the province's largest hospital, with 955 acute care beds. Hospital B has 440 acute care beds, and hospital C has 140 acute care and 100 extended care beds. All three hospitals offer primary and secondary care, are affiliated with the University of British Columbia (Vancouver, British Columbia) and accept referrals from throughout the province, with primary catchments being within the greater Vancouver area. Hospitals A and B are also tertiary care facilities. All three hospitals offer access to specialist services including internal medicine and respirology. The ICD-9-CM diagnostic codes used to classify the primary admission diagnosis were the same for all three hospitals.

\section{Data collection}

Data were retrospectively collected from health records by a contributing author $(\mathrm{KB})$ using a standardized data collection instrument developed for the project. Information regarding the index admission was obtained from progress notes made by physicians, as well as charting records and notes from nurses and other allied health care workers. Information bias was limited by the use of a set of 'practice' medical records, formal inclusion criteria, the use of a standardized data abstraction form and reviewing coding rules with health experts (20).

Variables were selected for analysis based on previous studies pertaining to readmission for an AECOPD and other chronic diseases $(8,13,16,17,21)$. Analyzed variables included demographics (eg, age and sex), admission statistics (number of admissions during the study period, dates of index admission and discharge, LOS during the index admission and date of first readmission after discharge from index admission), social characteristics (smoking status, occupation, living situation, home care status), Charlson comorbidity indices within one year preadmission (22), evidence of previous lung infections within one year of index admission, preadmission COPD therapy (eg, medications, home oxygen therapy, inhaled or systemic corticosteroid); functional status (mobility, activities of daily living); spirometry; and discharge care (referrals to physiotherapy and occupational therapy, as well as follow-up arrangements if any, to a family physician, an internist and/or a respirologist). Charts were also reviewed for documentation of previous participation in a COPD education program (including individual teaching, small-group sessions, video and audio tapes, and problem-solving sessions).

Comorbidity was quantified according to the Charlson index (22), which contains 19 categories of comorbidity that are primarily defined using the ICD-9-CM diagnosis codes. Each category has an associated weight that is based on the adjusted risk of one-year mortality. The overall comorbidity score reflects the cumulative increased likelihood of one-year mortality - the higher the score, the more severe the burden of comorbidity.

\section{Statistical analysis}

Sample size estimations suggested that 113 patients would be sufficient in the multiple logistic regression analysis to demonstrate an OR of 2.0 (between individuals readmitted and those not readmitted) - assuming a correlation of 0.2 between the covariates - at a significance level of $5 \%$ with $95 \%$ power (23). Values for continuous variables were reported as mean \pm SD unless otherwise stated. Because the primary end point was readmission, data from the 34 patients who died during the study period $(11 \%)$ were excluded from the analysis.

The association between variables and the risk of readmission were initially assessed with univariate logistic regression. Variables significant at $\mathrm{P} \leq 0.10$ were further combined and analyzed by stepwise logistic regression. Independent variables with high percentages of missing values (more than 10\%) were not included in the analysis. Hospitals were considered as potential covariates and were forced into the regression equation as 
dummy variables before testing other variables and could not be removed thereafter. Variables that retained significance were then entered into a stepwise multivariate regression analysis to compute the final predictive model for readmission outcome. All statistical analyses were performed using SPSS version 12.0 (SPSS Inc, USA) for Windows software (Microsoft, USA).

\section{RESULTS}

\section{Patient characteristics and readmission risk}

Between April 1, 2001, and December 31, 2002, 310 patients admitted to the three hospitals with an AECOPD met the study inclusion criteria (Table 1). The baseline characteristics of the cohort are shown in Table 2. One hundred sixty-six of the patients $(54 \%)$ were men, with a mean age of $74 \pm 12$ years. The cohort had a mean $\mathrm{FEV}_{1} \%$ predicted of $43 \pm 16$. Thirtyeight per cent of the subjects were current smokers, with an exposure ranging from 23 pack-years to 172 pack-years. Thirtyone per cent of patients were using home oxygen $\left(\mathrm{O}_{2}\right)$ before admission, 56\% had other chronic respiratory disease, 31\% had a history of lung infections (defined operationally based on the history documented in the chart as having any lung infection such as pneumonia or Mycobacterium tuberculosis within one year before the index admission), 37\% had a history of congestive heart failure (CHF) and 14\% had diabetes.

Of the 310 patients admitted to hospital for an AECOPD, 119 (38\%) had at least one subsequent hospital readmission for an AECOPD, 29 of which had two (9\%), and 23 (7\%) had three or more hospital readmissions - all verified from medical records. Among patients who were readmitted to hospital during the study period, the mean duration from the index admission to the first readmission was $5 \pm 4.08$ months $(n=80)$. The mean duration from second to third readmission was shorter $(2.57 \pm 2.65$ months $[n=26])($ Table 1$)$.

The medications prescribed before, during and following hospitalization are shown in Table 3. Care at the time of admission (first $24 \mathrm{~h}$ ) was analyzed using the total number of admissions $(n=503)$. The present analysis, therefore, included some patients more than once (ie, individuals who were readmitted); however, the purpose of the present analysis was to evaluate health care delivery - not the features of individual patients. Patient characteristics preadmission and at discharge were evaluated using the number of patients $(n=310)-$ not the number of admissions. Twenty-three per cent of patients were taking antibiotics before admission, suggesting that almost one-quarter of patients were failing an attempt at outpatient therapy for AECOPD. Twenty-one per cent of patients were using oral corticosteroids before admission. Inhaled corticosteroids were used by $45 \%$ of patients before admission, while $39 \%$ of patients were prescribed inhaled corticosteroids at discharge. Oral or parenteral corticosteroids were administered in the first $24 \mathrm{~h}$ in only $59 \%$ of AECOPD admissions. No association was found between the use of oral corticosteroids preadmission and the risk of readmission(s).

Univariate analysis was performed with baseline characteristics as independent variables and hospital readmissions as the dependent variables. Significant risk factors for readmission to hospital included home $\mathrm{O}_{2}$ use preadmission (OR 2.62; 95\% CI 1.58 to $4.32 ; \mathrm{P}=0.000$ ), a history of lung infection within one year before the index admission (OR 2.06; 95\% CI 1.25 to 3.40; $\mathrm{P}=0.005$ ), other respiratory disease (OR 1.99; $95 \% \mathrm{CI} 1.24$ to

\section{TABLE 1}

Number of admissions and readmissions during the study period (April 2001 to December 2002)

$\begin{array}{lc}\text { Patients, } \mathrm{n} & 310 \\ \text { Admissions, } \mathrm{n} & 503 \\ \text { Readmissions, } \mathrm{n}(\%) & 191(62) \\ 0 & 67(22) \\ 1 & 29(9) \\ 2 & 23(7) \\ \geq 3 & 5 \pm 4.08 \\ \text { Mean duration from the index admission to the first } & \\ \text { readmission, months (mean } \pm \text { SD) } & 2.57 \pm 2.65 \\ \text { Mean duration from second to third readmission, } \\ \text { months (mean } \pm \text { SD) }\end{array}$

TABLE 2

Baseline characteristics of patients hospitalized for a chronic obstructive pulmonary disease (COPD) exacerbation

\begin{tabular}{|c|c|}
\hline Characteristics & \\
\hline Male sex & $166(54)$ \\
\hline Age, years (mean $\pm \mathrm{SD}$ ) & $74 \pm 12$ \\
\hline $\mathrm{FEV}_{1}, \mathrm{~L}(\text { mean } \pm \mathrm{SD})^{*}$ & $1.01 \pm 0.9$ \\
\hline $\mathrm{FEV}_{1}, \%$ predicted $(\text { mean } \pm \mathrm{SD})^{*}$ & $43 \pm 16$ \\
\hline Smoking within one year & $118(38)$ \\
\hline Smoking history, pack-years (mean $\pm \mathrm{SD})^{*}$ & $56 \pm 29$ \\
\hline Home oxygen preadmission & $95(31)$ \\
\hline Formal home support ${ }^{\star \dagger}$ & $88(28)$ \\
\hline Home care nurse ${ }^{*}$ & $24(8)$ \\
\hline Living in a nursing home & $27(9)$ \\
\hline Community based PT/OT* & $14(5)$ \\
\hline Previous participation in a COPD education program* & $10(3)$ \\
\hline \multicolumn{2}{|l|}{ Difficulty with activities of daily living } \\
\hline Mobility $\ddagger$ & $100(32)$ \\
\hline Dressing & $176(57)$ \\
\hline Bathing & $100(32)$ \\
\hline Difficulty with instrumental activities of daily living* & $157(51)$ \\
\hline \multicolumn{2}{|l|}{ Charlson comorbidity } \\
\hline Other chronic respiratory disease ${ }^{\S}$ & $174(56)$ \\
\hline Congestive heart failure & $113(37)$ \\
\hline Musculoskeletal disease & $67(22)$ \\
\hline Diabetes & $43(14)$ \\
\hline Ischemic heart disease & $41(13)$ \\
\hline History of lung infection $\pi$ & $95(31)$ \\
\hline
\end{tabular}

Data presented as $n(\%)$ unless indicated otherwise. *Indicates variables with greater than $10 \%$ missing data; ${ }^{\dagger}$ Arrangements for any general medical and/or professional assistance with personal cares or daily activities inside the home; IInability to walk without assistance; §Any chronic respiratory disease aside from COPD; "Any previous description in the chart of a pulmonary infection (most commonly pneumonia and tuberculosis). FEV 1 Forced expiratory volume in $1 \mathrm{~s} ;$ PT/OT Physiotherapy/occupational therapy

3.21; $\mathrm{P}=0.005$ ), problems with dressing (OR 2.27; 95\% CI (1.32 to $3.91 ; \mathrm{P}=0.003)$, and previous participation in a COPD education program (OR 6.0; 95\% CI 1.21 to 29.73; $\mathrm{P}=0.041$ ) (Table 4).

Variables with a $\mathrm{P}>0.05$ but $\mathrm{P}<0.1$ (body mass index, LOS and having home care nursing) were considered for the multiple 
TABLE 3

Respiratory medication used during the study period

\begin{tabular}{|c|c|c|c|c|c|c|}
\hline \multirow[b]{2}{*}{ Medications } & \multicolumn{2}{|c|}{$\begin{array}{c}\text { Pre- } \\
\text { admission } \\
(n=310)\end{array}$} & \multicolumn{2}{|c|}{$\begin{array}{l}\text { First } 24 \mathrm{~h} \text { of } \\
\text { admission } \\
(\mathrm{n}=503)\end{array}$} & \multicolumn{2}{|c|}{$\begin{array}{l}\text { At discharge } \\
(n=310)\end{array}$} \\
\hline & $\mathbf{n}$ & $\%$ & $\mathbf{n}$ & $\%$ & $\mathbf{n}$ & $\%$ \\
\hline \multicolumn{7}{|l|}{ Beta-agonist bronchodilators } \\
\hline Short-acting & 164 & 53 & 476 & 95 & 195 & 63 \\
\hline Long-acting & 18 & 6 & 11 & 2 & 9 & 3 \\
\hline Anticholinergic bronchodilators & 168 & 54 & 447 & 89 & 175 & 57 \\
\hline Inhaled corticosteroids & 139 & 45 & 174 & 35 & 120 & 39 \\
\hline Parenteral corticosteroids & - & 81 & 16 & - & & \\
\hline Oral corticosteroids & 64 & 21 & 214 & 43 & 154 & 50 \\
\hline Antibiotics & 71 & 23 & 329 & 66 & 134 & 37 \\
\hline Combination inhalers & 39 & 13 & 6 & 1 & 24 & 8 \\
\hline
\end{tabular}

Note: The percentage of medication used in the preadmission and discharge columns was based on the number of patients ( $n=310$ ), while to follow the use of medication in patients with several readmissions during the study period, the percentage of medication use in the 'first 24 hours of admission' was based on the total number of admissions ( $n=503)$

\section{TABLE 4}

Comparison between patients experiencing one admission versus one or more readmissions (univariate analysis)

\begin{tabular}{|c|c|c|c|c|c|}
\hline Characteristics & $\begin{array}{c}\text { One } \\
\text { admission } \\
(n=191)\end{array}$ & $\begin{array}{c}\text { Read- } \\
\text { mission } \\
(n=119)\end{array}$ & & & \\
\hline Categorical variables & $\%$ & $\%$ & $\mathbf{P}$ & OR & $95 \% \mathrm{Cl}$ \\
\hline Men & 52.6 & 52 & 0.640 & 0.89 & $0.56-1.41$ \\
\hline Home $\mathrm{O}_{2}$ preadmission & 24 & 45 & $0.000^{*}$ & 2.62 & $1.58-4.32$ \\
\hline Formal home support $^{\dagger}$ & 36 & 44 & 0.325 & 1.35 & $0.78-2.33$ \\
\hline Home care nurse $^{\dagger}$ & 8 & 17 & 0.075 & 2.20 & $0.94-5.19$ \\
\hline Living in a nursing home & 10 & 7 & 0.409 & 0.65 & $0.28-1.54$ \\
\hline Community-based PT/OT' & 8 & 11 & 0.561 & 1.47 & $0.48-4.47$ \\
\hline $\begin{array}{l}\text { Previous participation in a } \\
\text { COPD education program }\end{array}$ & 17 & 55 & 0.041 & 6.00 & $1.21-29.73$ \\
\hline Current smoker & 39 & 42 & 0.542 & 1.17 & $0.72-1.89$ \\
\hline Living with someone & 57 & 53 & 0.543 & 0.85 & $0.53-1.38$ \\
\hline \multicolumn{6}{|l|}{ Activities of daily living } \\
\hline Problems with dressing ${ }^{\dagger}$ & 58 & 76 & $0.003^{*}$ & 2.27 & $1.32-3.91$ \\
\hline \multicolumn{6}{|l|}{ Charlson comorbidity } \\
\hline Diabetes & 18 & 7 & 0.004 & 0.32 & $0.14-0.72$ \\
\hline Congestive heart failure & 34 & 41 & 0.223 & 1.37 & $0.85-2.20$ \\
\hline Ischemic heart disease & 15 & 11 & 0.489 & 0.73 & $0.36-1.47$ \\
\hline Other respiratory disease & 50 & 66 & $0.005^{\star}$ & 1.99 & $1.24-3.21$ \\
\hline History of lung infection & 26 & 42 & $0.005^{\star}$ & 2.06 & $1.25-3.40$ \\
\hline Follow-up by respirologist & 41 & 50 & 0.102 & 1.47 & $0.93-2.34$ \\
\hline Continuous variables & $\begin{array}{c}\text { Mean } \pm \\
\text { SD }\end{array}$ & $\begin{array}{c}\text { Mean } \pm \\
\text { SD }\end{array}$ & $\mathbf{P}$ & OR & $95 \% \mathrm{Cl}$ \\
\hline Age, years & $74 \pm 12$ & $72 \pm 12$ & 0.229 & 0.99 & $0.97-1.01$ \\
\hline Length of stay, days & $11 \pm 13$ & $8 \pm 11$ & $0.074^{*}$ & 0.98 & $0.96-1.00$ \\
\hline Body mass index, $\mathrm{kg} / \mathrm{m}^{2 \dagger}$ & $25 \pm 7$ & $23 \pm 6.5$ & 0.074 & 0.95 & $0.90-1.00$ \\
\hline $\mathrm{FEV}_{1}, \mathrm{~L}^{\dagger}$ & $37 \pm 17$ & $29 \pm 12$ & 0.674 & 1.13 & $0.64-2.00$ \\
\hline
\end{tabular}

*Indicates $P$ values less than 0.1 (cutoff for inclusion in the multiple regression analysis). HIndicates variables with greater than $10 \%$ missing data. COPD Chronic obstructive pulmonary disease; FEV ${ }_{1}$ Forced expiratory volume in $1 \mathrm{~s}$; $\mathrm{O}_{2}$ Oxygen; PT/OT Physiotherapy/occupational therapy
TABLE 5

Final multivariate models of risk factors for readmission to hospital for acute exacerbations of chronic obstructive pulmonary disease

\begin{tabular}{lcccc}
\hline & & & \multicolumn{2}{c}{$95 \% \mathrm{Cl}$} \\
\cline { 4 - 5 } Variables in the equation & $\mathbf{P}$ & OR & Lower & Upper \\
\hline Use of home oxygen preadmission & 0.001 & 2.554 & 1.474 & 4.424 \\
History of lung infection & 0.048 & 1.727 & 1.005 & 2.967 \\
Other chronic respiratory disease & 0.030 & 1.779 & 1.057 & 2.994 \\
Length of stay & 0.002 & 0.439 & 0.262 & 0.737 \\
\hline
\end{tabular}

regression analysis. The variables 'previous participation in a COPD education program', 'body mass index', 'home care nursing' and 'problems with dressing' were not included in the multiple regression analysis because all of these variables were subject to greater than $10 \%$ missing data and, therefore, deemed unreliable. The forward stepwise multiple logistic regression model included the following variables: use of home $\mathrm{O}_{2}$ preadmission, comorbidities (history of lung infection and other chronic respiratory disease) and LOS (Table 5). An adjusted analysis was performed including hospitals as dummy variables to control for possible hospital factors that may potentially confound the association between variables and hospital readmission. Four variables that were found to be significant factors associated with readmission to a hospital in the logistic regression analysis included use of home $\mathrm{O}_{2}$ preadmission (OR 2.55; 95\% CI 1.47 to $4.42 ; \mathrm{P}=0.001$ ), a history of lung infections (OR 1.73; 95\% CI 1.01 to $2.97 ; \mathrm{P}=0.05$ ), other chronic respiratory disease (OR $1.78 ; 95 \%$ CI 1.06 to 2.99; $\mathrm{P}=0.03$ ) and $\operatorname{LOS}(\mathrm{OR} 0.44 ; 95 \%$ CI 0.26 to $0.74 ; \mathrm{P}=0.002$ ). There was no significant interaction between variables in the logistic regression analysis.

Comparison of the three hospitals surveyed

Comparative analysis among the three hospitals identified a significant difference in readmission rates. Hospital A had the highest rate of readmission (54\%), while hospital C had the lowest (18\%) and hospital B was in between (37\%). To explore underlying reasons for the differences in outcomes between the hospitals, both patient and health care-related factors were evaluated (Table 6).

Patient characteristics compared among the three hospitals included demographics, premorbid health characteristics and social characteristics. Fewer men were admitted to hospital C (39\%) compared with 59\% and 58\% for hospitals A and B, respectively. Hospital $\mathrm{C}$ also had the highest percentage of patients admitted who were not Canadian born (55\%) compared with hospitals A (29\%) and B (17\%). Regarding premorbid health characteristics, the average $\mathrm{FEV}_{1} \%$ predicted was lowest in hospital A $(33 \pm 10)$ and highest in hospital C $(56 \pm 19)$, suggesting an inverse relationship between $\mathrm{FEV}_{1}$ and the rate of hospital readmission in the three hospitals. There was also a higher percentage of home $\mathrm{O}_{2}$ use preadmission among patients admitted to hospital A (40\%) compared with hospital B (27\%) and hospital C (22\%). Furthermore, CHF was seen more often in hospital A (48\%) compared with hospitals B (29\%) and C (31\%). Of the social characteristics evaluated, no trends that correlated with the differences in the rates of readmission among the three hospitals were identified. 
Health care and delivery characteristics that were evaluated to explore the differences in outcomes among the three hospitals included admitting services, respiratory medications prescribed in the first $24 \mathrm{~h}$ of admission and follow-up care arrangements made at the time of discharge. Although all three hospitals primarily admitted AECOPD patients to respirology and internal medicine departments, hospital A had the highest rate of admission to family practice services (29\%) compared with both hospital B (3.2\%) and hospital C (10.4\%). Antibiotic use in the first $24 \mathrm{~h}$ of admission was higher in hospital C (88\%) than in hospitals A and B (59\% and 62\%, respectively). Hospital A, with the highest readmission rate, had the lowest rate of systemic corticosteroid (combined oral and parenteral) administration in the first $24 \mathrm{~h}$ of admission (45\% versus 73\% versus 59\% for hospitals A, B and C, respectively). Overall, follow-up arrangements made with physicians at the time of discharge did not seem to positively affect the rate of readmission.

\section{DISCUSSION}

The present study described the outcomes of 310 patients who experienced at least one AECOPD resulting in admission to one of three Vancouver area hospitals over a 20-month period during 2001 and 2002. Readmission rates for COPD patients were high. During the study period, $38 \%$ of subjects were readmitted at least once and the mean duration from the index admission to the first readmission was only $5 \pm 4.08$ months. A previously described cohort of 345 COPD patients (13) admitted to hospital for COPD exacerbations and followed for readmission in Spain found a similar rate. The authors reported a first readmission rate of $63 \%$ over a mean follow-up period of 1.1 years and a median time to first readmission of 186 days (13). The high frequency of readmission and the short time to readmission found in our study and that of Garcia-Aymerich et al (13), highlight the social and economic burden that COPD exerts on society.

\section{Patient characteristics and readmission risk}

Despite evaluating a wide range of both modifiable and nonmodifiable potential risk factors for hospital readmission, only a few clinical factors were found to be independently associated with COPD readmission in the present study. The preadmission use of home $\mathrm{O}_{2}$ was found to be associated with a higher risk of readmission in both univariate and logistic regression analyses. A number of previous studies $(7,9,11)$ have also reported home $\mathrm{O}_{2}$ as a risk factor associated with an increased risk of admission or frequent readmissions. It is likely that home $\mathrm{O}_{2}$ use is a marker of disease severity, and individuals with more advanced disease are at higher risk for readmission. Previous lung infections (within one year before index admission) and other chronic respiratory disease were also both associated with an increased risk of readmission in the logistic regression analyses. The presence of other chronic respiratory disease may increase susceptibility to readmission simply by compounding the impairment in lung function, or may impact overall systemic fitness and, therefore, the global ability to cope with acute illness. Individuals with documented previous lung infections within one year before admission may be at higher risk of readmission because increased frequency of chest infections leads to more frequent COPD exacerbations. With increased COPD severity, the likelihood of admission during exacerbations increases.
TABLE 6

Comparison of the three hospitals surveyed

\begin{tabular}{|c|c|c|c|}
\hline \multirow[b]{2}{*}{ Variable } & \multicolumn{3}{|c|}{ Hospital } \\
\hline & A & B & C \\
\hline \multicolumn{4}{|l|}{ Admissions $(n=310)$} \\
\hline Single admission & $54(46)$ & $73(64)$ & $64(82)$ \\
\hline 1 readmission & $33(28)$ & $24(21)$ & $10(13)$ \\
\hline 2 readmissions & $15(13)$ & $11(10)$ & $3(4)$ \\
\hline$\geq 3$ readmissions & $15(13)$ & $7(6)$ & $1(1)$ \\
\hline Total & 117 & 115 & 78 \\
\hline \multicolumn{4}{|l|}{ Patient characteristics $(n=310)$} \\
\hline Age, years (mean $\pm S D)$ & $76 \pm 10$ & $70 \pm 11$ & $75 \pm 15$ \\
\hline Men & $69(59)$ & $67(58)$ & $30(39)$ \\
\hline \multicolumn{4}{|l|}{ Ethnicity } \\
\hline Canadian born & $21(18)$ & $7(6)$ & $3(4)$ \\
\hline Foreign born & $34(29)$ & $19(17)$ & $43(55)$ \\
\hline Missing data & $62(53)$ & $89(77)$ & $32(41)$ \\
\hline \multicolumn{4}{|l|}{ Premorbid health characteristics } \\
\hline $\mathrm{FEV}_{1} \%$ predicted, $\mathrm{L}($ mean $\pm \mathrm{SD})$ & $33 \pm 10$ & $48 \pm 13$ & $56 \pm 19$ \\
\hline Preadmission home oxygen & $47(40)$ & $31(27)$ & $17(22)$ \\
\hline \multicolumn{4}{|l|}{ Charlson comorbidity } \\
\hline Congestive heart failure & $56(48)$ & $33(29)$ & $24(31)$ \\
\hline Other respiratory disease & $67(57)$ & $43(55)$ & $64(56)$ \\
\hline History of lung infection & $41(35)$ & $36(31)$ & $18(23)$ \\
\hline \multicolumn{4}{|l|}{ Social characteristics } \\
\hline Living with someone & $72(62)$ & $40(35)$ & $50(64)$ \\
\hline Formal home support & $40(34)$ & $28(24)$ & $20(26)$ \\
\hline
\end{tabular}

Health care and delivery characteristics ( $n=503$ patient encounters)

\begin{tabular}{lccc}
\hline Admitting services & \multicolumn{3}{l}{} \\
Respiratory medicine & $46(21)$ & $36(19.3)$ & $12(12.5)$ \\
Internal medicine & $69(32)$ & $98(52.4)$ & $61(63.5)$ \\
Family practice & $63(29)$ & $6(3.2)$ & $10(10.4)$ \\
Respiratory medication use in the first 24 h of admission & \\
Inhaled corticosteroids & $64(28)$ & $57(31)$ & $53(55)$ \\
Oral corticosteroids & $69(31)$ & $121(65)$ & $22(23)$ \\
Parenteral corticosteroids & $31(14)$ & $15(8)$ & $35(36)$ \\
Antibiotics & $129(59)$ & $116(62)$ & $84(88)$ \\
Postdischarge follow-up & & & \\
Family doctor & $122(56)$ & $145(78)$ & $49(51)$ \\
Respirologist & $69(31)$ & $143(77)$ & $24(25)$ \\
Internist & $9(4)$ & $69(37)$ & $7(7)$ \\
\hline
\end{tabular}

Data presented as $n(\%)$ unless indicated otherwise. FEV ${ }_{1}$ Forced expiratory volume in $1 \mathrm{~s}$

Patients readmitted to hospital were more likely to have shorter LOSs. However, previous studies $(21,24)$ have indicated that increased disease severity is associated with prolonged LOS. It may be that in our cohort, shorter LOS was an indication of premature discharge before the clinical and social aspects of the admission were fully resolved and, thus, patients were more likely to return to hospital. It is possible that very short hospital admissions do not allow for appropriate convalescence and discharge planning, while very long LOSs represent individuals with severe disease requiring long-term therapy or those with more precarious social circumstances that make discharge planning more difficult. 
No association was found between current smoking and the risk of COPD admission or readmission. This finding supports the result of a previous study by Kessler et al (9) that found no differences between current smokers and the risk of COPD readmission. An explanation has been proposed by Anthonisen (23), who suggested that severely ill patients with COPD spontaneously quit smoking probably in response to their symptoms and disability. Prospective studies including a wider range of COPD severity would help to clarify this issue.

The $\mathrm{FEV}_{1} \%$ predicted was not a predictor of hospital readmission for an AECOPD in the present study. Several studies have similarly reported a lack of association between $\mathrm{FEV}_{1} \%$ precicted and COPD exacerbations and admissions $(9,25,26)$; however, others $(13,15,27,28)$ have found lower $\mathrm{FEV}_{1}$ or severity of $\mathrm{FEV}_{1}$ impairment to be predictive of a higher risk of COPD admission and readmission. It is possible that the lack of association in the present and other studies was the result of inadequate statistical power rather than a true lack of association. Alternatively, the lack of association between $\mathrm{FEV}_{1}$ and hospital readmission may be due to relatively limited variation in the $\mathrm{FEV}_{1}$ across the study population.

\section{Comparison of the three hospitals}

The rates of hospital readmission varied among the three hospitals. Comparison of the patient and health care characteristics provided an opportunity to explore possible explanations for the differences in readmission rates. The cohort of patients admitted to the hospital with the highest rate of readmission (hospital A) appeared to have more severe COPD as demonstrated by the lowest mean $\mathrm{FEV}_{1}$ and highest percentage of home $\mathrm{O}_{2}$ use before admission. It may be that severity of COPD is the primary explanation for the variation in the rates of readmission. In support of this conclusion, a recent study published by Gonzalez et al (29) in 2008, found that patients with LTOT had a lower $\mathrm{FEV}_{1} \%$ predicted, and the use of LTOT was independently related to the risk of readmission for patients with moderate to severe COPD.

Overall, the hospital with the highest rate of readmission for AECOPD (hospital A) had the lowest rate of systemic corticosteroid administration in the first $24 \mathrm{~h}$ of admission. This variation in the standard of care may, in part, explain the difference in hospital readmission rates. If this is the case, this finding would support the implementation of standardized care pathways for AECOPD based on current best management guidelines. It is interesting to note that hospital A also had the highest percentage of AECOPD admissions to the family practice service compared with other hospitals. Whether the relationship between readmission rates and admitting service is a consequence of immediate corticosteroid use or a result of more general overall care differences remains unclear and requires a more direct evaluation.

\section{Limitations}

The primary limitation of the present analysis is the retrospective design. As with all retrospective studies, caution must be exercised when interpreting the results because selection, information and recall bias cannot be completely accounted for. It is possible that not all readmissions were captured because some patients may have been readmitted to a hospital other than the three surveyed in the present study. However, the three hospitals studied provide all of the acute care for the Vancouver area; thus, it is unlikely that a significant number of readmissions to other hospitals were missed. The frequency of exacerbations in the year before admission was likely underestimated because only exacerbations for which a discharge report or a hospital record was available were included in an attempt to limit recall bias. Finally, the diagnosis of AECOPD relied on clinical assessments that were not standardized across time and location before the chart review.

\section{CONCLUSION}

We found a high rate of readmission for AECOPD within a 20-month study period. Furthermore, there was significant variability in the readmission rate among three hospitals within the same city. This variability may be a consequence of differences in the populations served by each or may reflect differences in health care delivery that impact patient outcomes. Prospective studies are warranted to explore these possibilities further because the former may identify modifiable patient characteristics while the latter may identify modifiable health care characteristics. A history of lung infections within one year before admission, the presence of other chronic respiratory disease, the use of home $\mathrm{O}_{2}$ before admission and longer duration of admission were significantly associated with a higher likelihood of being readmitted to hospital. These characteristics may be markers of COPD severity or identify individuals with overall more precarious health and/or social circumstances. These results raise the possibility that these variables could be used as identifiers of patients at highest risk for frequent exacerbations and readmissions.

ACKNOWLEDGEMENTS: We are grateful to Dr Penny Brasher, Dr Michael Schulzer and Dr Mohsen Sadatsafavi for their data management and statistical advice. Dr FitzGerald is a MSFHR Distinguished Scholar Recipient as well as a BC Lung/CIHR Scientist.

DISCLOSURE: The present study was funded by an unrestricted educational grant from GlaxoSmithKline.

\section{REFERENCES}

1. Ernst PP, Bourbeau J, Rainville B, Benayoun S, Suissa S. Underestimation of COPD as a cause of death. Eur Respir J 2000;16(Suppl 31):13s.

2. O'Donnell DE, Aaron S, Bourbeau J, et al. State of the art compendium: Canadian Thoracic Society recommendations for the management of chronic obstructive pulmonary disease. Can Respir J 2004;11(Suppl B):7B-59B.

3. Rochon PA, Katz JN, Morrow LA, et al. Comorbid illness is associated with survival and length of hospital stay in patients with chronic disability: A prospective comparison of three comorbidity indices. Med Care 1996;34:1093-110.

4. Sin DD, Tu JV. Are elderly patients with obstructive airway disease being prematurely discharged? Am J Respir Crit Care Med 2000;161:1513-7.

5. Centre for Chronic Disease Prevention and Control. Editorial Board for Respiratory Disease in Canada, Health Canada, Ottawa, Canada, 2001.

6. Bahadori K, FitzGerald JM. Risk factors of hospitalization and readmission of patients with COPD exacerbations. Int J Chron Obstruct Pulmon Dis 2007;2:241-51.

7. Garcia-Aymerich J, Monso E, Marrades RM, et al. Risk factors for hospitalization for a chronic obstructive pulmonary disease exacerbation. EFRAM study. Am J Respir Crit Care Med $2001 ; 164: 1002-7$. 
8. Lau AC, Yam LY, Poon E. Hospital re-admission in patients with acute exacerbation of chronic obstructive pulmonary disease. Respir Med 2001;95:876-84.

9. Kessler R, Faller M, Fourgaut G, Mennecier B, Weitzenblum E. Predictive factors of hospitalization for acute exacerbation in a series of 64 patients with chronic obstructive pulmonary disease. Am J Respir Crit Care Med 1999;159:158-64.

10. Burge PS, Calverley PM, Jones PW, Spencer S, Anderson JA, Maslen TK. Randomised, double blind, placebo controlled study of fluticasone propionate in patients with moderate to severe chronic obstructive pulmonary disease: The ISOLDE trial. BM] 2000;320:1297-303

11. Wang Q, Bourbeau J. Outcomes and health-related quality of life following hospitalization for an acute exacerbation of COPD. Respirology 2005;10:334-40.

12. Bourbeau J, Ernst P, Cockcoft D, Suissa S. Inhaled corticosteroids and hospitalisation due to exacerbation of COPD. Eur Respir J 2003;22:286-9.

13. Garcia-Aymerich J, Farrero E, Felez MA, Izquierdo J, Marrades RM, Anto JM. Risk factors of re-admission to hospital for a COPD exacerbation: A prospective study. Thorax 2003;58:100-5.

14. Groenewegen KH, Schols AM, Wouters EF. Mortality and mortality-related factors after hospitalization for acute exacerbation of COPD. Chest 2003;124:459-67.

15. Miravitlles M, Guerrero T, Mayordomo C, Sanchez-Agudo L, Nicolau F, Segu JL. Factors associated with increased risk of exacerbation and hospital admission in a cohort of ambulatory COPD patients: A multiple logistic regression analysis. The EOLO Study Group. Respiration 2000;67:495-501.

16. Cao Z, Ong KC, Eng P, Tan WC, Ng TP. Frequent hospital re-admissions for acute exacerbation of COPD and their associated factors. Respirology 2006;11:188-95.

17. Gudmundsson G, Gislason T, Janson C, et al. Risk factors for rehospitalisation in COPD: Role of health status, anxiety and depression. Eur Respir J 2005;26:414-9.
18. Garcia-Aymerich J, Barreiro E, Farrero E, Marrades RM, Morera J, Anto JM. Patients hospitalized for COPD have a high prevalence of modifiable risk factors for exacerbation. Eur Respir J 2000;16:1037-42.

19. Wilkinson TMA, Donaldson GC, Hurst JR, Seemungal TAR, Wedzicha JA. Early therapy improves outcomes of exacerbations of chronic obstructive pulmonary disease. Am J Respir Crit Care Med 2004;169:1298-303.

20. Gilbert EH, Lowenstein SR, Koziol-McLain J, Barta DC, Steiner J. Chart reviews in emergency medicine research: Where are the methods? Ann Emerg Med 1996;27:305-8.

21. Horn SD, Sharkey PD, Buckle JM, Backofen JE, Averill RF, Horn R. The relationship between severity of illness and hospital length of stay and mortality. Med Care 1991;29:305-17.

22. Charlson ME, Pompei P, Ales KL, MacKenzie CR. A new method of classifying prognostic comorbidity in longitudinal studies: Development and validation. J Chronic Dis 1987;40:373-83.

23. Anthonisen NR. Smoking, lung function and mortality. Thorax 2000;55:729-30.

24. Mushlin AI, Black ER, Connolly CA, Buonaccorso KM, Eberly SW. The necessary length of stay in chronic pulmonary disease. JAMA 1991;266:80-3.

25. Decramer M, Gosselink R, Troosters T, Verschueren M, Evers G. Muscle weakness is related to utilization of health care resources in COPD patients. Eur Respir J 1997;10:417-23.

26. Osman LM, Godden DJ, Friend JAR, Legge JS, Douglas JG. Quality of life and hospital re-admission in patients with chronic obstructive pulmonary disease. Thorax 1997;52:67-71.

27. Vestbo J, Rasmussen FV. Respiratory symptoms and FEV ${ }_{1}$ as predictors of hospitalization and medication in the following 12 years due to respiratory disease. Eur Respir J 1989;2:710-5.

28. Emerman CL, Effron D, Lukens TW. Spirometric criteria for hospital admission of patients with acute exacerbation of COPD. Chest 1991;99:595-9.

29. Gonzalez C, Servera E, Marin J. Importance of non-invasively measured respiratory muscle overload among the causes of hospital readmission of COPD patients. Chest 2008;133:941-7. 


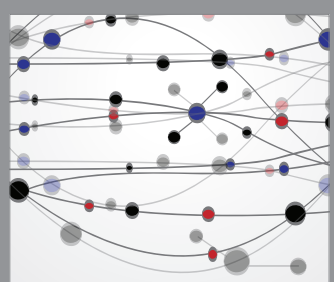

The Scientific World Journal
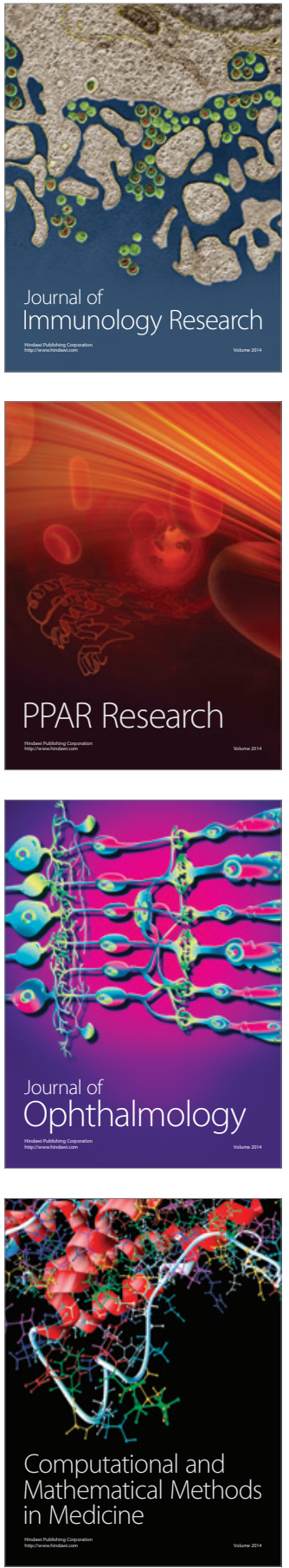

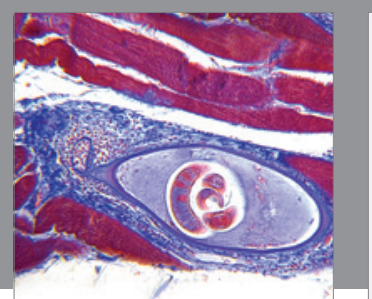

Gastroenterology Research and Practice

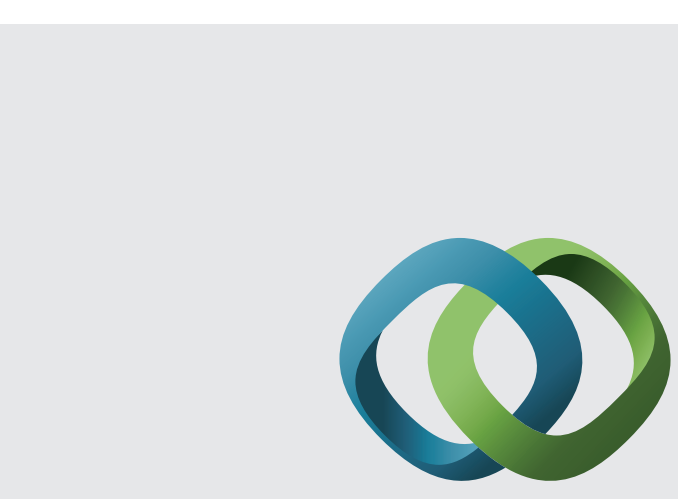

\section{Hindawi}

Submit your manuscripts at

http://www.hindawi.com
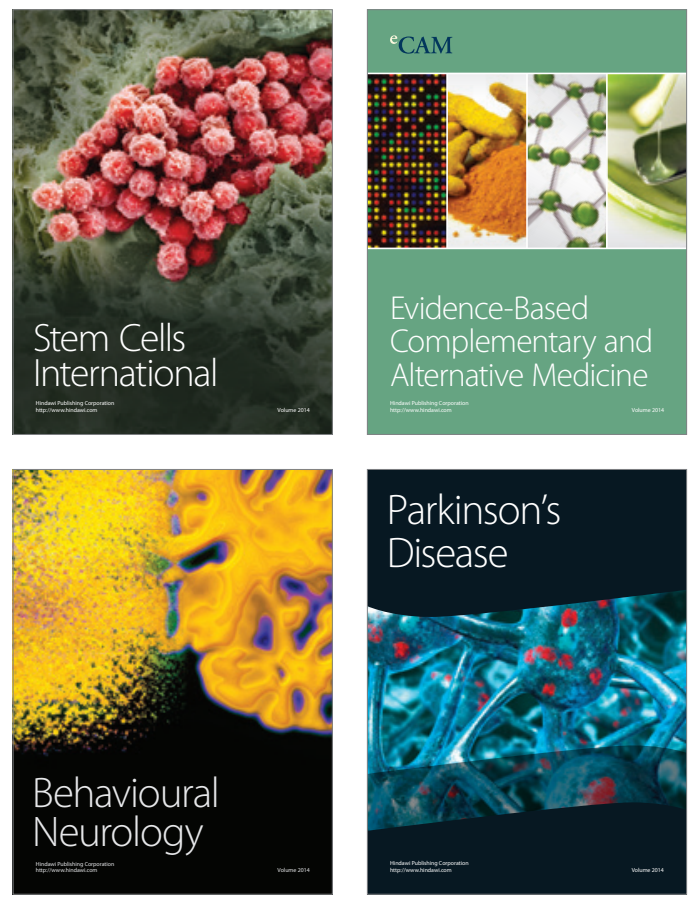
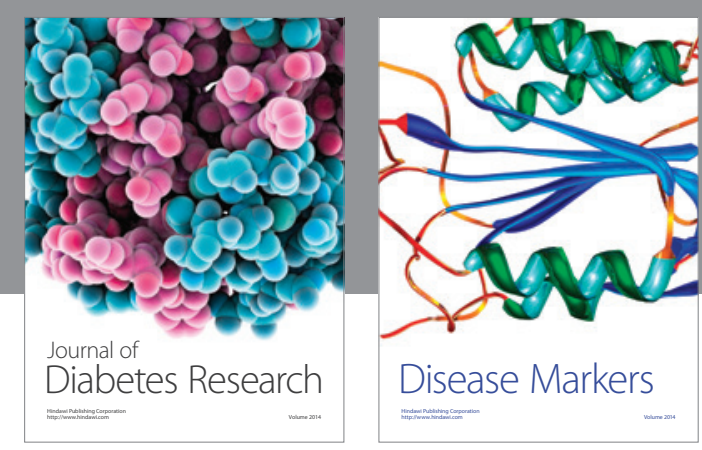

Disease Markers
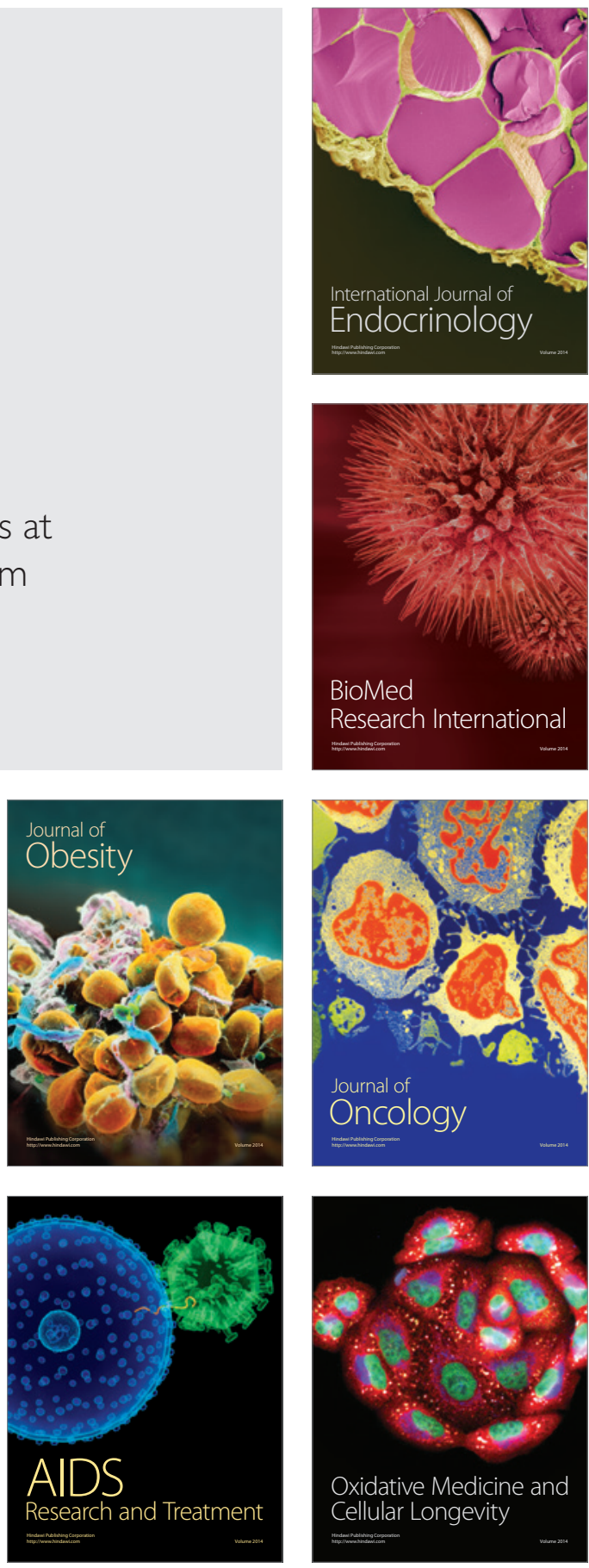